\title{
Incidence of Childhood Diabetes in Children Aged Less than 15 Years and Its Clinical and Metabolic Characteristics at the Time of Diagnosis: Data from the Childhood Diabetes Registry of Saxony, Germany
}

\author{
Angela Galler ${ }^{a}$ Thoralf Stange $^{b} \quad$ Gabriele Müller $^{b} \quad$ Andrea Näke $^{c}$ \\ Christian Vogel $^{d}$ Thomas Kapellen $^{a}$ Heike Bartelt $^{a}$ Hildebrand Kunath $^{b}$ \\ Rainer Koch ${ }^{b}$ Wieland Kiess ${ }^{a}$ Ulrike Rothe ${ }^{b}$ \\ for the Childhood Diabetes Registry in Saxony, Germany \\ a University Hospital for Children and Adolescents, University of Leipzig, Leipzig, ${ }^{\mathrm{b}}$ Institute for Medical Informatics \\ and Biometrics, University of Dresden, and ' Children's Hospital, University of Dresden, Dresden, and \\ ${ }^{\mathrm{d} C h i l d r e n ' s ~ H o s p i t a l, ~ C h e m n i t z ~ H o s p i t a l, ~ C h e m n i t z, ~ G e r m a n y ~}$
}

\section{Key Words}

Epidemiology • Diabetes incidence • Type 1 diabetes •

Ketoacidosis

\begin{abstract}
Aims: The Childhood Diabetes Registry in Saxony, Germany, examined the incidence and metabolic characteristics of childhood diabetes. Methods: In the federal state of Saxony, newly diagnosed cases of diabetes in children and adolescents aged less than 15 years were registered continuously from 1999 until 2008. Family history, date of diagnosis, clinical and laboratory parameters were obtained. Reported cases were ascertained by public health departments as an independent data source and verified using the capturerecapture method. Results: A total of 865 children and adolescents with newly diagnosed diabetes were registered in Saxony. About $96 \%$ of them were classified as having type 1 diabetes, $0.6 \%$ had type 2 diabetes, $2.4 \%$ had maturityonset diabetes of the young (MODY), and $1.4 \%$ had other types of diabetes. The age-standardized incidence rate of type 1 diabetes was estimated at 17.5 per 100,000 children
\end{abstract}

\section{KARGER}

Fax +4161306 1234

E-Mail karger@karger.ch

www.karger.com (c) 2010 S. Karger AG, Basel

$1663-2818 / 10 / 0744-0285 \$ 26.00 / 0$

Accessible online at:

www.karger.com/hrp per year. Completeness of ascertainment as calculated by the capture-recapture method amounted to $93.6 \%$. At the time of diagnosis, $27.1 \%$ of children with type 1 diabetes had ketoacidosis, $1.5 \%$ had a blood $\mathrm{pH}<7.0$, and $1.1 \%$ were unconscious. Conclusion: The registry provided data about the incidence rates and clinical presentation of childhood diabetes in a defined German population. We observed higher incidence rates compared to previous surveys.

Copyright $\odot 2010$ S. Karger AG, Basel

\section{Introduction}

Type 1 diabetes is one of the most frequent chronic metabolic disorders in children and adolescents. A global rise in the incidence of type 1 diabetes in children and adolescents has been reported over the past decades [1-7]. Putative causes explaining this increase are still not yet clarified. Mean incidence rates of type 1 diabetes vary considerably depending on the geographic region [2-7]. Particularly China and South American countries have very low incidence rates. Apart from regions with low to 
intermediate incidence rates ranging between 5 and 20 per 100,000 children/adolescents per year, there are areas with incidence rates as high as $27.5-42.9$ per 100,000 children/adolescents per year. Northern European countries such as Finland and Sweden, and Canada have the highest incidence rates ranging between 30 and 40 per 100,000 children/adolescents per year [2-7]. Incidence rates of countries in Central Europe (with the exception of Sardinia) vary from 8 to 18 per 100,000 children/adolescents per year $[2,4,5,8-11]$. The incidence for type 1 diabetes in German children aged 0-14 years was estimated at 13 per 100,000 per year for 1987-1998 and at 15.5 per 100,000 per year for 1999-2003. This incidence was estimated from a registry undertaken in the southwestern part of Germany, a region covering about $10 \%$ of the total German area [12-14]. The registry of the former German Democratic Republic which was run from 1960 until 1989 reported incidence rates between 7.4 and 13.8 per 100,000 per year [15].

Previously perceived as disease of the elderly, most recently children and adolescents are more frequently affected by type 2 diabetes. The number of type 2 diabetes cases diagnosed is subject to regional aspects and ethnic origin. Type 2 diabetes is more frequently found in African-American children and adolescents and in offspring of Pima Indians compared to children and adolescents of Caucasian origin [16-19]. Epidemiological data on other types of diabetes in childhood is scare. Only a few data exist about the prevalence of maturity-onset diabetes of the young (MODY) in certain regions. Studies in Scandinavian countries estimate the prevalence of MODY at $2 \%$ on all diabetes cases and varying between 2 and 5\% in relation to non-insulin-dependent diabetes cases [16-19].

The Childhood Diabetes Registry of Saxony was established to collect prospective epidemiological data on childhood diabetes in a defined German population. Furthermore, it was to provide data on clinical and metabolic characteristics of type 1 diabetes at the time of diagnosis. Considering the increasing incidence of childhood diabetes worldwide and evaluation of clinical and metabolic characteristics of childhood diabetes, consecutive registries will provide the basis for more efficient socioeconomic and public health management in the future.

\section{Methods}

Description of the Study Population

The Childhood Diabetes Registry of Saxony was established in 1999 to consecutively register all children and adolescents with newly diagnosed diabetes aged less than 15 years and living in
Saxony. Saxony is a federal state of Germany bordering Poland and the Czech Republic to the east. In Saxony, the population under the age of 15 years decreased from 578,271 in 1999 to 445,523 in 2008 with a minimum of 436,305 in 2005 (49\% male, $51 \%$ female). These mid-year estimates were obtained from the statistical district department of Saxony (Federal State Department Saxony).

\section{Data Collection}

All 34 pediatric clinics and pediatric departments of Saxony participated in the registry. Diagnostic criteria for childhood diabetes were according to ISPAD criteria for children and adolescents (ISPAD Clinical Practice Consensus Guidelines 2006-2007) [16]. Regular meetings and professional certified education were offered to the participating pediatricians. Personal data (date of birth, gender, birth weight, municipality of residence), family history of type 1 diabetes, date of diagnosis, and clinical and biochemical data at onset of diabetes were collected by a standardized questionnaire. Date of diagnosis was defined as the date of the first insulin injection in the case of type 1 diabetes. For other types, diabetes was diagnosed when oral glucose tolerance test met the diagnostic criteria for diabetes (fasting plasma glucose of or above $7.0 \mathrm{mmol} / \mathrm{l}(126 \mathrm{mg} / \mathrm{dl})$, or 2-hour plasma glucose of or above $11.1 \mathrm{mmol} / \mathrm{l}(200 \mathrm{mg} / \mathrm{dl}))$ or repeated elevated random plasma glucose levels of or above $11.1 \mathrm{mmol} / \mathrm{l}(200 \mathrm{mg} / \mathrm{dl})$ were recorded [16]. Pediatricians assessed clinical and biochemical parameters, duration of clinical signs and symptoms, and level of consciousness. Parameters such as blood glucose level, hemoglobin $\mathrm{Alc}(\mathrm{HbA1c}), \mathrm{pH}$, base excess (BE) and bicarbonate were measured at the time of hospital admission in the routine laboratory of the respective hospital. Ketoacidosis was defined as $\mathrm{pH}<7.3$, severe ketoacidosis was defined as $\mathrm{pH}<7.1$ [20]. Duration of hospital stay was documented.

The Childhood Diabetes Registry of Saxony was approved by the Ethical Committee of the Medical Faculty of the University of Leipzig and written informed consent was obtained from all parents.

\section{Ascertainment of Cases}

Completeness of ascertainment was assessed in collaboration with regional Public Health Departments of Aue, Chemnitzer Land, Dresden, Freiberg, Leipzig, Riesa-Grossenhain, Vogtlandkreis, Weisseritzkreis, and Zittau, providing an independent data source. Public health departments performed school examinations in children and adolescents at the age of 6,11 and 15 years, and obtained information regarding medical history, chronic diseases, medical treatment and the name and address of the treating pediatrician and hospital from the parents. The completeness of ascertainment was calculated according to the capture-recapture method [21].

\section{Statistical Analysis}

Total as well as gender- and age-specific incidence rates per 100,000 person-years were calculated for each calendar year. All incidence rates are age-standardized using the European standard population [22] and represented as standardized incidence rates (SIRs) per 100,000 person-years in total as well as over time between two 5-year periods (first: 1999-2003, latest: 2004-2008). The $95 \%$ confidence intervals (CI) for SIRs are based on a normal approximation using standard errors of estimations. The Wald 
Table 1. Age-SIR of type 1 diabetes per 100,000 person-years in the two 5 -year periods

\begin{tabular}{lllll}
\hline Time period & Population & Cases & IR (raw) & SIR (Europe) ${ }^{1}$ \\
\hline $1999-2003$ & $2,615,995$ & 412 & $15.7(14.2-17.3)$ & $15.7(14.2-17.3)$ \\
$2004-2008$ & $2,215,710$ & 415 & $18.7(17.0-20.6)$ & $19.2(17.4-21.1)$ \\
\hline
\end{tabular}

${ }^{1}$ Incidence rate (IR) and age-standardized incidence rate (SIR) per 100,000 personyears $(95 \% \mathrm{CI})$.

Table 2. Age-specific incidence rates of type 1 diabetes per 100,000 person-years: a raw and b standardized by using the European standard population

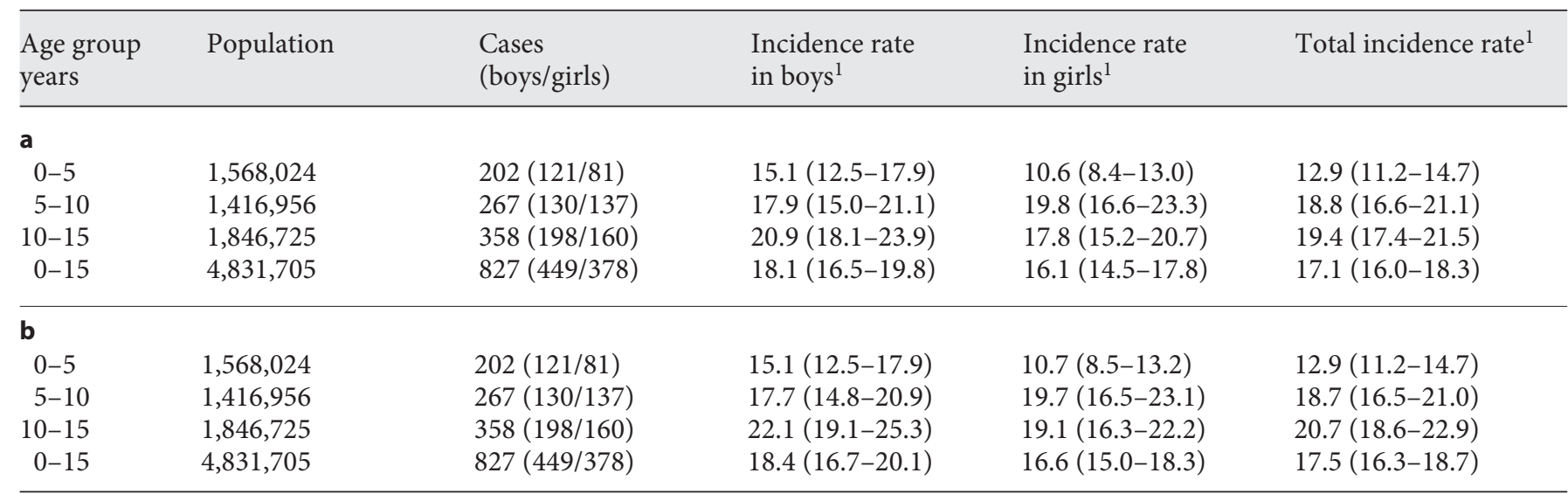

${ }^{1}$ Incidence rate per 100,000 person-years (95\% CI).

test was used to compare the SIRs of the two time periods. Clinical data are presented as mean and standard deviation and CI. We employed the Kruskal-Wallis test to analyze differences between more than two groups. Student's t test and variance analysis, with Tukey-adjusted multiple comparisons between estimated means, were performed to compare quantitative variables between groups. The $\chi^{2}$ test was used to compare categorical variables. Statistical parameters were estimated using Microsoft Excel and SPSS program 16.0. The level of significance was defined as $\alpha=0.05$.

\section{Results}

A total of 865 children and adolescents aged $0-15$ years were identified with newly diagnosed diabetes during the 10 -year observation period. Of those, 827 children and adolescents $(95.6 \%)$ had type 1 diabetes $(54.3 \%$ male, $45.7 \%$ female) and $5(0.6 \%)$ were classified as having type 2 diabetes. A total of 33 children (3.8\%) had other types of diabetes. Of these, 21 children (2.4\%) had MODY which was confirmed by genetic analysis and 12 children
(1.4\%) had diabetes secondary to another disease, mostly cystic fibrosis. Completeness of ascertainment was estimated at $93.6 \%$.

\section{Incidence of Type 1 Diabetes}

Age-SIR of type 1 diabetes per 100,000 person-years was estimated at 17.5 (95\% CI 16.3-18.7) for the entire observation period. SIR increased significantly from 15.7 (95\% CI 14.2-17.3) per 100,000 person-years in the time period 1999-2003 up to 19.2 (95\% CI 17.4-21.1) per 100,000 person-years in the time period $2004-2008$ ( $<<$ 0.001 ) (table 1). $24.3 \%$ of all children with type 1 diabetes were less than 5 years old, $32.3 \%$ were between the age of 5 and 10 years, and the majority of children (53.3\%) were between the age of 10 and 15 years. Table $2 a$ and $b$ depicts raw and SIRs by age. Peak incidence rates were observed in April, autumn and winter (between 26.6 and 24.0 per 100,000 person-years) whereas the lowest incidence was observed in June (12.1 per 100,000 person-years) (fig. 1). 


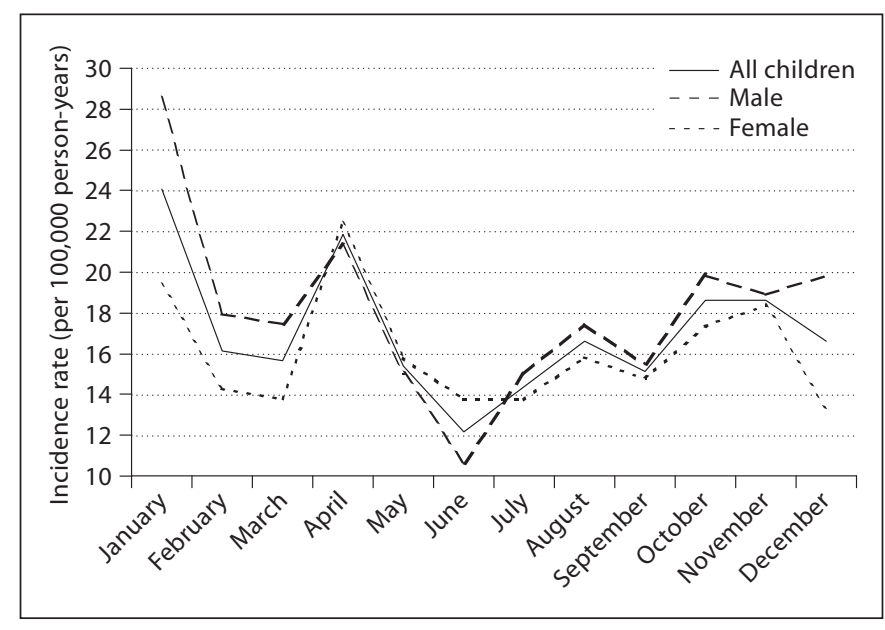

Fig. 1. Monthly incidence rates of type 1 diabetes in children aged less than 15 years. Mean monthly incidence rates per 100,000 person-years are depicted for the time period 1999-2008. Peak incidence rates were observed in April, autumn and winter. The lowest incidence was observed in June (12.1 per 100,000 personyears).

\section{Incidence of Other Types of Diabetes}

The incidence rate of type 2 diabetes was 0.10 (95\% CI 0.04-0.23) per 100,000 person-years for the time period 1999-2008. Incidence of MODY was 0.43 (95\% CI $0.27-$ $0.64)$. MODY 2 (mutation in glucokinase gene) was diagnosed in 10 children ( $48 \%$ of all cases with MODY) and MODY 3 (mutation in hepatocyte nuclear factor- $1 \alpha$ gene) was present in 11 children (52\%).

\section{Characteristics at the Time of Diagnosis of Type 1 \\ Diabetes}

Mean duration of symptoms like polydipsia and polyuria until diagnosis was $2.8 \pm 2.4$ weeks (95\% CI 2.6-2.9). Mean age at onset of type 1 diabetes was $8.6 \pm 4.0$ years (95\% CI 8.3-8.8). Mean age at onset was not significantly lower $(7.7 \pm 4.3$ years; 95\% CI 6.3-9.0) in the children with parental history of type 1 diabetes. Out of all children with newly diagnosed type 1 diabetes, 5.1\% had a parental history of type 1 diabetes (in $3.5 \%$ of cases mothers were affected, in $1.7 \%$ of cases fathers were affected). $9.1 \%$ of children had second-degree relatives affected by type 1 diabetes. Mean $\mathrm{HbAlc}$ was estimated at $11.2 \pm$ $2.6 \%(95 \%$ CI 11.0-11.4) at onset of type 1 diabetes. HbA1c was significantly higher in children aged $10-15$ years (mean HbAlc $11.9 \pm 2.7 \%$; 95\% CI 11.6-12.2\%) compared to children under the age of 5 years (mean HbAlc $10.1 \pm 1.9 \%$; $95 \%$ CI 9.8-10.3\%; $\Delta$ 1.8\%; $95 \%$ CI 1.4-2.2\%; $\mathrm{p}<0.001)$.

\section{Frequency of Ketoacidosis}

At time of diagnosis, $27.1 \%$ of hospitalized children were diagnosed with ketoacidosis. The highest proportion of ketoacidosis was found in children under the age of 5 years $(30.8 \%)$, whereas $22.1 \%$ of children aged between 5 and 10 years had ketoacidosis at the time of diagnosis. The frequency of ketoacidosis was $28.8 \%$ in children and adolescents aged 10-15 years. Frequency of ketoacidosis was not statistically different between the age groups $(\mathrm{p}=0.06)$. There was no difference in frequency of ketoacidosis in boys and girls $(p=0.68)$. In $6.6 \%$ of all children with newly diagnosed type 1 diabetes, $\mathrm{pH}$ was $<7.1$ (severe ketoacidosis). The lowest $\mathrm{pH}$ measured at the time of diagnosis was 6.8. There were no significant differences regarding the frequency of severe ketoacidosis across the age groups $(8.6 \%$ in children under the age of 5 years, $5.2 \%$ in the age group $5-10$, and $6.9 \%$ in the age group $10-15$ years; $p=0.38$ ). Neither the incidence of ketoacidosis nor the incidence of severe ketoacidosis changed between the first and latest 5 -year period ( $p=$ 0.14 and $p=0.42$ ). 9.5\% of children and adolescents with parental history of type 1 diabetes had ketoacidosis compared to $29.3 \%$ of children and adolescents without parental history, which was significantly higher $(\mathrm{p}=0.006)$. A total of 9 children (1.1\%) were unconscious at the time of hospital admission; 8 of these unconscious children were older than 8 years of age and 1 was 5 years old. One boy aged 1.9 years died from ketoacidosis and cerebral edema.

Mean duration of hospitalization of children with newly diagnosed type 1 diabetes was $14.9 \pm 6.3$ days (95\% CI 14.5-15.4). Mean duration was significantly longer in 1999 (19.2 \pm 6.7; CI 17.8-20.5) compared to 2008 (11.9 \pm 4.7; CI 10.9-13.0; $\Delta$ 7.2; 95\% CI 5.6-8.9; $\mathrm{p}<0.001)$.

\section{Discussion}

Various studies have reported a global increase in the incidences of type 1 and type 2 diabetes [1-7]. We describe the results from the consecutive Childhood Diabetes Registry accomplished in the federal state of Saxony from 1999 to 2008. The registry provided epidemiological data on childhood diabetes with a good level of ascertainment. Therefore the registry of Saxony yields a reliable estimate of type 1 diabetes in Germany. Age-SIR of childhood type 1 diabetes (17.5 per 100,000 per year) in Saxony between 1999 and 2008 is similar to previously published incidence rates in Germany between 1999 and 2003 (17.3 per 100,000 per year) [23]. Divergences may be 
due to the difference in survey periods and incidence rates may also differ by region. Incidence rates calculated by the registry in Baden-Württemberg, southern Germany, from 1987 to 1998 and 1993 to 1998, ranged between 12.9 and 14.3 per 100,000 per year [12,13]. Between 1999 and 2003 the incidence rate in Baden-Württemberg was 15.5 per 100,000 [14] and consequently similar to our calculated incidence rate in Saxony within the same survey period (15.7 per 100,000 person-years). Ehehalt et al. [23] reported an increase in incidence by $3.8 \%$ per year for the period from 1987 to 2003 . We also observed a significant increase in incidence of type 1 diabetes in Saxony between the first and latest 5-year period (from 15.7 per 100,000 person-years in $1999-2003$ up to 19.2 per 100,000 person-years in 2004-2008). Additionally, our estimated incidence rates were significantly higher compared to those previously assessed in the same region. The registry of the former German Democratic Republic reported incidence rates ranging between 7.4 and 13.8 per 100,000 per year from 1960 until 1989 [15]. There was no registry in eastern Germany between 1989 and 1999. Therefore the registry of Saxony is currently the only registry in the region of the former German Democratic Republic. Lifestyle changes over time may account for the increasing incidence rates between 1960 and 2006. Environmental factors have a significant effect on the pathogenesis of type 1 diabetes and may contribute to the increasing incidence rates of our registry compared to previous surveys $[1,9,11]$.

Moreover, we found a higher incidence of type 1 diabetes in boys, with the highest rate in children under 5 years. This gender disparity was also observed in other European countries $[4,24,25]$ and North America [10]. The underlying pathomechanisms explaining this gender difference are still not clear [24]. However, recent observations suggest that the manifestation of disease occurs earlier in boys than girls. No conclusion about the shift of incidence rates towards younger children can be made from the Saxon registry due to the short observation period and the lack of epidemiological data in children older than 15 years.

An advantage of this survey is the provision of incidence rates of type 2 diabetes and MODY. To date, there are only few epidemiological data on type 2 diabetes and MODY in children and adolescents available in Europe. We found low incidence rates of type 2 diabetes in children under the age of 15 years which is in concordance to studies previously published $[16,18,26]$. Data from the USA, comparing Caucasian and Indian children, are in accordance with our results, indicating that the preva-

Diabetes Incidence in Saxony, Germany lence of type 2 diabetes is low in Caucasian children and adolescents [26]. However, one important limitation should be pointed out. Because our data are based on known cases of diabetes only, the incidence of type 2 diabetes is probably underestimated especially with respect to the increasing prevalence of childhood overweight and obesity in Germany [27]. In comparison to the low incidence of childhood type 2 diabetes, the incidence rate of MODY was higher in the Saxon registry compared to other surveys [16-18, 28]. This finding probably suggests an underestimated incidence of MODY in other surveys. However, geographical differences may also account for the various incidence rates. For instance, in France, MODY 2 is more prevalent in contrast to England, where MODY 3 is more frequent [28]. Moreover, MODY 3 is typically diagnosed in children and adolescents at a later age compared to MODY 2 [28]. Therefore, depending on the age groups in different surveys, incidence rates may vary enormously.

Data on metabolic characteristics at the time of diagnosis of type 1 diabetes revealed very high frequencies of ketoacidosis in all children and adolescents and remarkably also in very young children: $30.8 \%$ of children under the age of 5 years had ketoacidosis. Worldwide, great differences regarding the frequencies of diabetic ketoacidosis are reported [29-31]. In developing countries the rate of ketoacidosis is much higher compared to developed countries [29-31]. Approximately 25\% of new patients with diabetes present with diabetic ketoacidosis in the USA [30, 31]. In Europe, the frequency of ketoacidosis varies between the different geographical regions [2933]. In the region of Parma, Italy, almost $0 \%$ of children and adolescents present with ketoacidosis at onset of type 1 diabetes [31]. This very low incidence was attributed to a campaign designed for prevention of primary ketoacidosis in the area of Parma [31]. In contrast, in Saxony we found a higher percentage of ketoacidosis (27.1\%). Similar findings were reported by Neu et al. [33] from the registry in Baden-Württemberg, Germany, within the same survey period: $26.3 \%$ of children and adolescents with newly diagnosed type 1 diabetes presented with ketoacidosis. In line with the data from the literature, diabetic ketoacidosis is very common in younger children [34]. The time of onset may impact on the rate of future complications such as cerebral edema $[31,32]$. Data of the Saxon registry may assist in planning public health strategies and may support campaigns for primary ketoacidosis prevention as currently practiced in Italy [31].

In summary, our data are in agreement with previously reported incidence rates in Europe. Further re- 
search is needed to identify risk factors and define pathomechanisms responsible for the observed increase in the incidence of childhood diabetes. Worryingly, diabetic ketoacidosis in children and adolescents is still very common at the time of diagnosis of type 1 diabetes. Because of the serious and life-threatening complications of diabetic ketoacidosis, prevention by education campaigns for the general population and healthcare professionals are recommended and further evaluation is needed.

\section{Acknowledgments}

The authors thank all participating pediatricians and Public Health Departments of Saxony for their collaboration. We thank Katrin Grumbt for her valuable assistance. The Childhood Diabetes Registry of Saxony was supported by Roche Diagnostics, but did not bias the outcome of the survey in any way.

\section{Members of the Childhood Diabetes Registry in Saxony}

Kreiskrankenhaus Altenburg, Kinderabteilung; EKA Erzgebirgsklinikum Annaberg gGmbH, Klinik für Kinder- und Jugendmedizin; HELIOS Klinikum Aue, Klinik für Kinder- und Jugendheilkunde; Klinikum Bautzen-Bischofswerda, Klinik für
Kinder- und Jugendmedizin; Helios Klinik Borna, Abteilung Pädiatrie; Klinikum Chemnitz gGmbH, Klinik für Kinder- und Jugendmedizin; DRK Gemeinnützige KH GmbH Sachsen KH Rabenstein, Chemnitz, Kinderklinik; Universitätsklinikum der TU Dresden, Klinik und Poliklinik für Kinderheilkunde; Städtisches Krankenhaus Dresden-Neustadt, Kinderklinik; Kreiskrankenhaus Löbau/Klinik Ebersbach, Kinderabteilung; Kliniken Erlabrunn gGmbH, Klinik für Pädiatrie; Kreiskrankenhaus Freiberg gGmbH, Kinderklinik; KKH Freital GmbH, Kinderklinik; KKH Rudolf Virchow Glauchau gGmbH, Kinderabteilung; Städtisches Krankenhaus Görlitz GmbH, Klinik für Kinder- und Jugendmedizin; KKH Herzberg, Kinderabteilung; Klinikum Hoyerswerda gGmbH, Klinik für Kinder- und Jugendmedizin; Universität Leipzig, Universitätsklinik und Poliklinik für Kinder und Jugendliche; Städtisches Klinikum St. Georg Leipzig, Klinik für Kindermedizin; HELIOS Krankenhaus Leisnig, Abteilung Kinder- und Jugendmedizin; KH Lichtenstein gGmbH, Abteilung Pädiatrie; Kreiskrankenhaus Meissen, Abteilung Pädiatrie; Landkreis Mittweida $\mathrm{KH}$ gGmbH, Abteilung Pädiatrie; Vogtland Klinikum Plauen $\mathrm{GmbH}$, Klinik für Kinder- und Jugendmedizin; Kreiskrankenhaus Pirna, Kinderklinik; Kliniken des Landkreises Riesa-Grossenhain/Kreiskrankenhaus Riesa, Kinderabteilung; KKH Rodewisch/Obergöltzsch, Pädiatrische Abteilung; KKH Torgau Johann Kentmann gGmbH, Abteilung für Kinderheilkunde und Jugendmedizin; Kreiskrankenhaus Weisswasser, Abteilung Pädiatrie; Pleissental-Klinik Werdau, Abteilung Pädiatrie; Sächsisches Krankenhaus Hubertusburg Wermsdorf, Kinderabteilung; KKH Wurzen, Kinderabteilung; Kreiskrankenhaus Zittau, Kinderklinik; Heinrich-Braun-Krankenhaus Zwickau, Klinik für Kinder- und Jugendmedizin.

\section{References}

1 Aamodt G, Stene LC, Njølstad PR, et al; the Norwegian Childhood Diabetes Study Group: Spatiotemporal trends and age-period-cohort modeling of the incidence of type 1 diabetes among children aged $<15$ years in Norway 1973-1982 and 1989-2003. Diabetes Care 2007;30:884-889.

2 Harjutsalo V, Sjöberg L, Tuomilehto J: Time trends in the incidence of type 1 diabetes in Finnish children: a cohort study. Lancet 2007;371:1777-1782.

3 International Diabetes Federation: Diabetes in children epidemiology. Pediatr Diabetes 2007;8:10-18.

4 Karvonen M, Viik-Kajander M, Moltchanova E, et al, for the Diabetes Mondiale Project Group: Incidence of childhood diabetes type 1 worldwide. Diabetes Care 2000;23:15161526.

5 Onkamo P, Väänänen S, Karvonen M, Tuomilehto J: Worldwide increase in incidence of type 1 diabetes - the analysis of the data on published incidence trends. Diabetologia 1999;42:1395-1403.

6 Soltész G: Diabetes in the young: a paediatric and epidemiological perspective. Diabetologia $2003 ; 46: 447-454$.
7 Soltesz G, Patterson CC, Dahlquist G, Eurodiab Study Group: Worldwide childhood type 1 diabetes incidence - what can we learn from epidemiology? Pediatr Diabetes 2007;8: 6-14.

8 Carle F, Gesuita R, Bruno G, et al; for the RIDI Study Group: Diabetes incidence in 0to 14-year age-group in Italy. Diabetes Care 2004;27:2790-2797.

9 Eurodiab ACE Study Group: Variation and trends in incidence of childhood diabetes in Europe. Lancet 2000;355:873-876.

10 Newhook LA, Curtis J, Hagerty D, et al: High incidence of childhood type 1 diabetes in the Avalon Peninsula, Newfoundland, Canada. Diabetes Care 2004;27:885-888.

11 Tuomilehto J, Karvonen M, Pitkäniemi J, et al; and the Finnish Childhood Type 1 Diabetes Registry Group: Record-high incidence of type 1 (insulin-dependent) diabetes mellitus in Finnish children. Diabetologia 1999; 42:655-660.

12 Neu A, Kehrer M, Hub R, Ranke B: Incidence of IDDM in German children aged 0-14 years. A 6-year population-based study (1987-1993). Diabetes Care 1997;20:530533.
13 Neu A, Ehehalt S, Willasch A, et al: Rising incidence of type 1 diabetes in Germany. 12year trend analysis in children $0-14$ years of age. Diabetes Care 2001;24:785-786.

14 Patterson CC, Dahlquist GG, Gyürüs E, Green A, Soltesz G, and the Eurodiab Study Group: Incidence trends for childhood type 1 diabetes in Europe during 1989-2003 and predicted new cases 2005-2020: a multicentre prospective registration study. Lancet 2009;373:2027-2033.

15 Michaelis D, Jutzi E, Heinke P: 30jährige Inzidenz- und Prävalenztrend des juvenilen Typ 1 Diabetes in der ostdeutschen Bevölkerung. Diab Stoffw 1993;2:245-250.

16 Craig ME, Hattersley A, Donaghue K: International Society for Pediatric and Adolescent Diabetes. ISPAD Clinical Practice Consensus Guidelines 2006-2007. Definition, epidemiology and classification. Pediatr Diabetes 2006;7:343-351.

17 Hattersley AT: Heterogeneity in type 2 diabetes: lessons from maturity-onset diabetes of the young. Diabetic Rev Int 1998;15:1524. 
18 Ledermann HM: Is maturity-onset diabetes at young age (MODY) more common in Europe than previously assumed? Lancet 1995; 345:648.

19 Lehto M, Wipemo C, Ivarsson SA, et al: High frequency of mutations in MODY and mitochondrial genes in Scandinavian patients with familial early-onset diabetes. Diabetologia 1999;42:1131-1137.

20 Wolfsdorf J, Craig ME, Daneman D, Dunger D, Edge J, Lee WRW, Rosenbloom A, Sperling MA, Hanas R: ISPAD Clinical Practice Consensus Guidelines 2006-2007. Diabetic ketoacidosis. Pediatr Diabetes 2007;8:28-42.

21 Bruno G, LaPorte RE, Merletti F, et al: National diabetes programs. Application of capture-recapture to count diabetes? Diabetes Care 1994;17:548-556.

22 WHO 2009. www.gbe-bund.de

23 Ehehalt S, Blumenstock G, Willasch AM, et al; DIARY Study Group Baden-Württemberg: Continuous rise in incidence of childhood type 1 diabetes in Germany. Diabet Med 2008;25:755-757.
24 Songini M, Casu A: Epidemiology of childhood diabetes. Acta Biomed 2005;76:19-25.

25 Svensson J, Carstensen B, Mortensen HB, Borch-Johnsen K, Danish Study Group of Childhood Diabetes: Early childhood risk factors associated with type 1 diabetes - is gender important? Eur J Epidemiol 2005;20: 429-434.

26 Fagot-Campagna A, Saaddine JB, Flegal KM, Beckles GL: Third National Health and Nutrition Examination Survey. Diabetes, impaired fasting glucose, and elevated $\mathrm{HbAlc}$ in US adolescents: the Third National Health and Nutrition Examination Survey. Diabetes Care 2001;24:834-837.

27 Kalies H, Lenz J, von Kries R: Prevalence of overweight and obesity and trends in body mass index in German pre-school children, 1982-1997. Int J Obes Relat Metab Disord 2002;26:1211-1217.

28 Velho G, Froguel P: Genetic, metabolic and clinical characteristics of maturity-onset diabetes of the young. Eur J Endocrinol 1998; 138:233-239.

29 Raine JE, Donaldson MDC, Savage MO, Hintz RL: Practical Endocrinology and Diabetes in Children, ed 2. Malden/MA, Blackwell, 2006.
30 Rewers A, Klingensmith G, Davis C, et al: Diabetic ketoacidosis at onset of diabetes: the SEARCH for Diabetes in Youth Study. Diabetes 2005;54:A63.

31 Vanelli M, Chiari G, Ghizzoni L: Effectiveness of a prevention program for diabetic ketoacidosis in children. Diabetes Care 1999; 22:7-9.

32 Vanelli M, Scarabello C, Fainardi V: Available tools for primary ketoacidosis prevention at diabetes diagnosis in children and adolescents. 'The Parma campaign'. Acta Biomed 2008;79:73-78.

33 Neu A, Willasch A, Ehehalt S, Hub R, Ranke MB; DIARY Study Group Baden-Wuerttemberg: Ketoacidosis at onset of type 1 diabetes mellitus in children - frequency and clinical presentation. Pediatr Diabetes 2003;4:77-81.

34 Pinkey JH, Bingley PJ, Sawtell PA, Dunger DB, Gale EA: Presentation and progress of childhood diabetes mellitus: a prospective population based study. Diabetologia 1994; 37:70-74. 